\title{
Treatment of Wilson's Disease with Zinc. I. Oral Zinc Therapy Regimens
}

\author{
Gretchen M. Hill, George J. Brewer, Ananda S. Prasad, Connie R. Hydrick and \\ Deborah E. HartmanN \\ Departments of Human Genetics and Internal Medicine and the Clinical Research Center, University of Michigan, Ann Arbor, \\ Michigan 48109; Department of Internal Medicine, Wayne State University and Wayne State University School of Medicine, \\ Detroit, Michigan 48201; Veterans Administration Hospital, Allen Park, Michigan 48101; and University of Missouri-Columbia, \\ College of Home Economics, Department of Human Nutrition Foods and Foods Systems Management,
}

Columbia, Missouri 65211

The standard therapy for preventing copper accumulation in Wilson's disease, D-penicillamine, has been a life-saving drug, but it has many side effects and some patients are completely intolerant. We have been using oral zinc as another approach to the therapy for Wilson's disease, with copper balance studies as the key initial assessment of the adequacy of a given dose or regimen of zinc therapy. We earlier reported that an intensive regimen of zinc (zinc taken every $4 \mathrm{hr}$ ) was effective in controlling copper balance. We have now shown with balance studies that a simplified zinc therapy regimen of $50 \mathrm{mg}$ zinc taken 3 times per day is effective in controlling copper balance. Preliminary work presented here with other simplified regimens also indicate their effectiveness. These studies increase the data base, in terms of copper balance, for zinc therapy of Wilson's disease, and expand the dose range and regimens of zinc which have been shown to control copper balance.

Wilson's disease is an autosomal recessive disease of copper accumulation, with copper toxicity manifesting primarily in the liver and/or brain. The disease is progressive and ultimately fatal if untreated. The search for substances to remove copper brought forth the use of penicillamine in 1956 by Walshe (1), and many lives have been saved by this type of chelation therapy. How-

Received June 11, 1986; accepted December 11, 1986.

This study was supported in part by Grants NIH NIAMDDK R01AM26050, NIAMDDK R01-AM31401, NHLBI Sickle Cell Branch HL16008, Veterans Administration Medical Research Funds, and the Herrick, Sage and Ervin Foundations, and the Clinical Research Center of the University of Michigan Hospital, which, in turn, is supported by USPHS Grant SM01-FR-42, and by the Generic Pharmaceutical Industry Association and four pharmaceutical companies (Henry Schein, Inc., Rugby Labs, Sandoz Pharmaceuticals and Lemmon Company).

This work has been done under an Investigational New Drug (IND) approved from the Food and Drug Administration. Recently, the Lemmon Company has adopted zinc acetate as a treatment for Wilson's disease under the Orphan Drug Act. The Lemmon Company (Sellersville, Pa.) anticipates applying for a New Drug Application (NDA) for the use of zinc acetate in the therapy of Wilson's disease in the near future. After approval of an NDA, zinc acetate would be generally available for the treatment of Wilson's disease.

Address reprint requests to: George J. Brewer, M.D., Professor of Human Genetics and Internal Medicine, University of Michigan Medical School, Department of Human Genetics, 4708 Med Sci II, Box 0618, Ann Arbor, Michigan 48109-0618. ever, an appreciable percentage of Wilson's disease patients have an initial hypersensitivity reaction to penicillamine (2), and some have sufficient side effects that life long therapy with penicillamine becomes difficult or impossible (3). Recently, Trien, which acts by chelation and urinary excretion of copper as does D-pencillamine, has been approved by the Food and Drug Administration. Much less is known about the long-term toxicity of this drug than with either penicillamine or zinc.

Zinc, a known antagonist of copper, has been introduced as an alternative therapy for Wilson's disease. As early as 1946 (4), zinc had been shown to produce copper deficiency in experimental animals. In 1977, we observed (5) that sickle cell anemia patients being treated with zinc developed copper deficiency. As a follow-up, we began trials using zinc as a therapeutic agent for the treatment of Wilson's disease (6).

Meanwhile, a group in Holland published the first paper on zinc treatment of Wilson's disease (7), presenting primarily clinical evidence of efficacy without balance studies. This group also cited earlier work in an unpublished thesis by Schouwink (Academisch Proetschrift Amesterdam, Van der Wiel, Arnhem, 1961, Utrecht, Holland) reporting negative copper balance in two patients while on zinc therapy. The Holland group has published additional clinical follow-up studies showing zinc efficacy from the clinical standpoint (8) and have employed ${ }^{64}$ copper uptake to evaluate zinc therapy (9).

In our work, copper balance has been the cornerstone measure for initial indication of adequacy of a given dose of zinc in each patient. Our original zinc therapy regimen was intensive and tedious. It involved taking zinc 5 or 6 times per day, avoiding food by an hour with each dose. Thus, the objectives of the work presented herein were to determine if smaller doses of zinc and less tedious regimens would be effective in controlling copper balance in Wilson's disease patients.

\section{MATERIALS AND METHODS}

Patients and Subjects. Included in this study were 14 adult Wilson's disease patients who had the clinical and biochemical features of Wilson's disease, partially summarized in Table 1, and who were mentally capable of giving informed 
TABLE 1. Characteristics of patient population

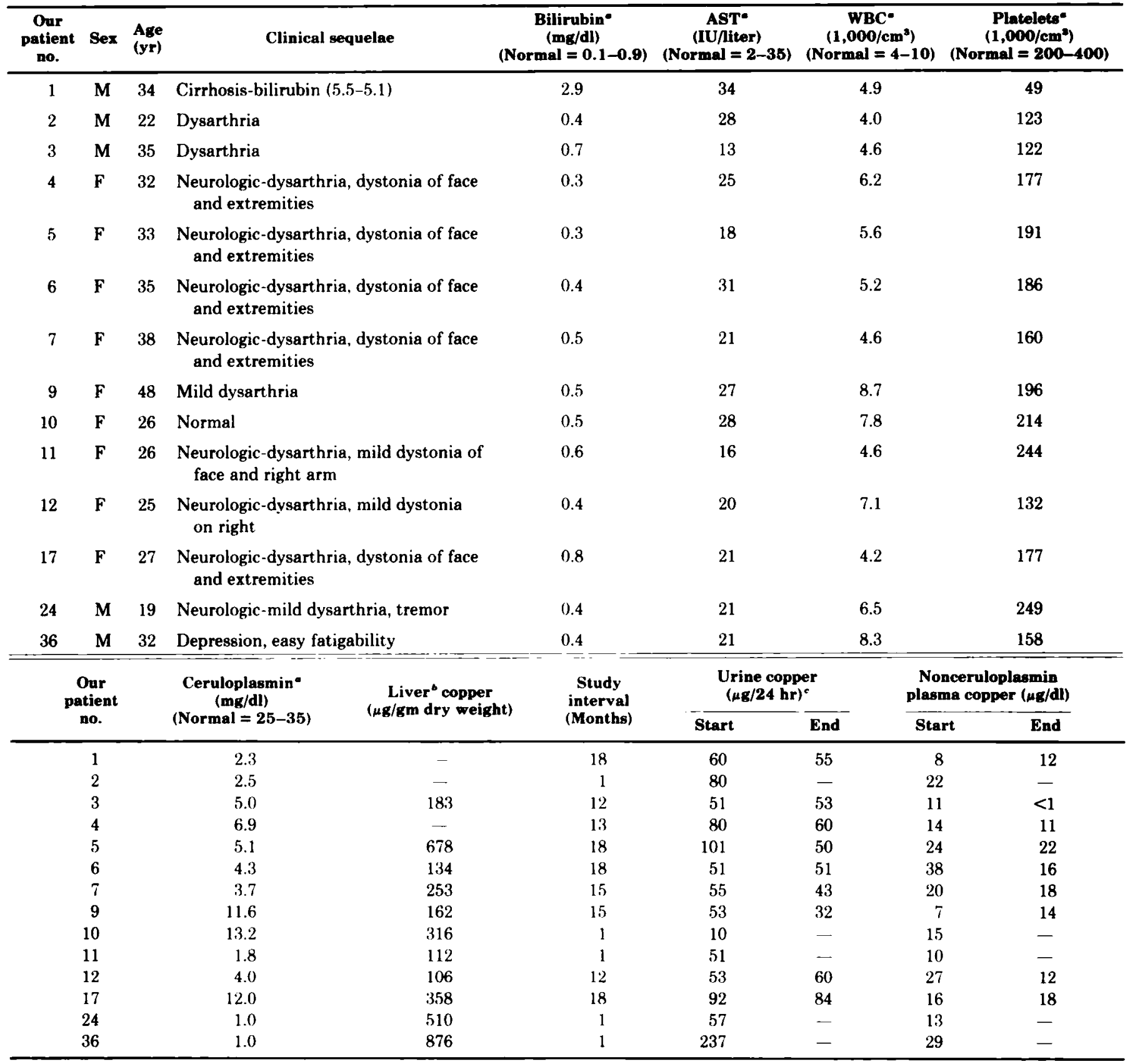

- These values are the average of several determinations in each case.

"Values at the time our studies began.

-Values presented are the mean of three 24 -hr determinations using an IL 451 AA, which is quite reliable in this range. Normal values are 45 $\mu \mathrm{g} / 24 \mathrm{hr}$ or lower. Typical values for untreated or only partially decoppered Wilson's disease patients are $150 \mu \mathrm{g} / 24 \mathrm{hr}$ or higher.

consent or consent was given by their legal guardian. Thirteen of the patients had been on penicillamine therapy for several years and were in stable clinical condition. These patients had good evidence of adequate decoppering, as manifested, for example, by relatively low liver copper on biopsy, the continual absence of Kayser-Fleischer rings, low urinary copper excretion in the absence of penicillamine and low nonceruloplasmin plasma copper (a measure of readily available copper). The fourteenth patient (No. 36 of Table 1) had been newly diagnosed and had not been treated with anticopper medication.

Eleven of the patients had presented with neurological symptoms and carried residual neurological sequelae (Table 1). One patient (No. 36) had presented with behavioral abnormalities, one (No. 10) had been diagnosed while clinically normal and one (No. 1) had presented with frank liver disease. While only this patient had liver disease at the clinically detectable level, 10 other patients had evidence of subclinical cirrhosis and hypersplemism as manifested by thrombocytopenia (Table 1 ). Many of these patients also had a tendency toward leukopenia (Table 1). Serum enzymes derived from the liver were in the normal range, as exemplified by AST levels (Table 1).

Normal volunteers known to be in good health and in the age range of the Wilson's disease patients were participants in the perspiration study. This research was performed according 
to the Declaration of Helsinki, informed consent was obtained in all cases and the University of Michigan Human Experimentation Committee approved these studies.

Study Design. Our first objective in this work was to document that a particular simplified regimen of zinc therapy (we selected $50 \mathrm{mg}$ given three times per day for reasons elaborated on in the "Discussion") would adequately control copper balance in Wilson's disease patients. A second objective was to compare copper balance in Wilson's disease patients on various other simplified regimens of zinc therapy. With respect to this latter objective, ideally one would like to study each patient on each regimen, thus allowing direct comparison of the effectiveness of each regimen on the identical group of patients. However, certain practical limitations, such as rarity of the disease, the amount of time required of each patient per balance (14 days) and the large costs involved in the hospital admissions, prevented the attainment of that ideal. Because of these limitations, the number of patients studied with the various regimens other than $50 \mathrm{mg} 3$ times per day ( 10 patients at this dose) was 3 or 4 each. Three patients volunteered for four studies, five patients for two studies and the remainder was studied only once. An equilibration period of at least 3 months was allowed on each new dose to be studied in patients who were studied more than once. Normally, 1 to 3 weeks of zinc therapy is adequate to produce a maximal therapeutic effect (6).

Zinc Therapy Regimens. The zinc therapy regimens used for this study were: 25 or $50 \mathrm{mg}$ zinc 3 times per day, given at 0700,1500 and $2300 \mathrm{hr} ; 50 \mathrm{mg}$ zinc 2 times per day, given at 1000 and $2200 \mathrm{hrs}$ and $25 \mathrm{mg}$ zinc 4 times per day, given at $0700,1100,1600$ and $2100 \mathrm{hr}$. All medication schedules for zinc administration avoided food and beverages for $1 \mathrm{hr}$ before and after zinc ingestion. This is necessary because many foods have substances which chelate or bind zinc and prevent its effectiveness $(10,11)$. Elemental zinc was supplied as zinc acetate in tablets except for Patient 6, for whom zinc sulfate capsules were used per her request. Zinc acetate is used because without concomitant food ingestion, it has been our experience that zinc sulfate can be irritating to the stomach, while the acetate salt is well-tolerated. All medications were assayed in our laboratory to guarantee accuracy of zinc dose.

Copper Balance. All patients stopped their previous anticopper therapy and began taking zinc on the regimen to be studied at least 3 months prior to admission to the Clinical Research Center at the University of Michigan. No food or beverage (except deionized-distilled water) was to be consumed for $1 \mathrm{hr}$ before or after taking each dose of the zinc. Foods and beverages to be consumed daily were selected by the patient, purchased prior to admission in sufficient quantity for the entire balance period and were prepared in the metabolic kitchen at the Clinical Research Center. Thus, the same foods and beverages were consumed each day during the balance period to guarantee constant copper intake. Diet selection by the patient was to reflect as closely as possible the diet consumed in their daily life and not necessarily a "well-balanced" diet. However, sufficient calories and protein were consumed to maintain body weight during the balance period. Food was prepared in stainless steel vessels and served on or in paper containers shown not to contribute copper or zinc to the foods. Duplicate daily food and beverage composites, identical to that consumed by the patient, were prepared twice during each balance period for copper and zinc analysis.

Fecal excretion during the balance period was delineated by $50 \mathrm{mg}$ U.S. food color FDC\#1 at 0700 on the first and last days of the constant diet. All balance periods were a minimum of 10 days in duration. All stools were collected in preweighed polypropylene containers and stored at $4^{\circ} \mathrm{C}$ until preparation for analysis. Twenty-four hour urine samples were collected in acid washed containers, measured, aliquoted into $250 \mathrm{ml}$ polyethylene containers and frozen at $-20^{\circ} \mathrm{C}$ until analyzed for zinc and copper. Plasma was drawn into trace element-free syringes and anticoagulated with heparin which had passed through a chelex 100 column to remove zinc and copper. After centrifugation, plasma was frozen at $-20^{\circ} \mathrm{C}$.

Forearm Perspiration Collection for Copper Analysis. One forearm, including the hand of the patient or subject to be studied, was scrubbed with soap and rinsed 3 times with deionized-distilled water, and then wrapped with a plastic food wrap bag shown to be free of copper. The patient or subject sat in a sauna at a temperature of $93^{\circ} \mathrm{F}$ for $30 \mathrm{~min}$ and the perspiration from the arm collected in the bottom of the plastic bag. The perspiration was transferred to a plastic tube and the copper concentration determined.

Analyses. Homogenized food composites and stool samples were weighed, lyophilized, reweighed and digested with redistilled nitric acid (Baker Instra-Analyzed, J. T. Baker Chemical Co., Phillipsburg, NJ) until digestion was complete. Appropriately diluted plasma, digested food and fecal samples, and undiluted urine and perspiration were analyzed for copper and zinc concentration by atomic absorption spectrophotometry on an IL451 (Instrumentation Laboratory, Inc., Wilmington, Mass.) or a Perkin-Elmer 306 (Perkin-Elmer, Norwalk, Conn.). In all cases, the appropriate standards were used with the sample.

Interpretation of Copper Balance. Apparent copper balance is defined as copper intake (food) minus copper excreted (fecal plus urine). In this study, we classified each balance result into 1 of 3 categories, which are as follows: (i) positive balance-greater than $+0.25 \mathrm{mg}$ positive balance per day; (ii) negative balance $-a$ more negative balance than -0.15 mg per day, and (iii) neutral balance-between $+0.25 \mathrm{mg}$ and $-0.15 \mathrm{mg}$ per day. The average loss of $0.34 \mathrm{mg}$ copper per day from the skin's surface has been reported in normal subjects (12). Although the surface loss of copper in Wilson's disease has not been measured quantitatively, our preliminary data (presented in the "Results" section) indicate similar losses in perspiration of normal and Wilson's disease patients. Since surface losses were not considered in the balance data presented herein, an apparent positive balance of $+0.25 \mathrm{mg}$ per day would result in an actual negative balance averaging $-0.09 \mathrm{mg}$. Since the daily intake of copper is about $1.0 \mathrm{mg}$ per day, an apparent balance of $+0.25 \mathrm{mg}$ would have to be in error by $0.09 \mathrm{mg}$, or almost $10 \%$ of the total intake, before even a slight positive balance would go undetected. A loss of copper greater than 0.15 mg per day represents an appreciable loss of copper and seems a reasonable point below which to define a balance as definitely negative.

Statistical Methods. Student's t test (13) was utilized to compare the copper concentration in forearm perspiration of Wilson's disease patients and controls, and to compare the mean copper balance of patients taking $150 \mathrm{mg}$ zinc per day with the copper balance in patients taking a smaller dose of zinc. Linear regression (13) of copper balance data on the total zinc dose was also performed.

\section{RESULTS}

Concentrations of Copper in Perspiration. Data on copper concentration in forearm perspiration (Table 2) indicate that Wilson's disease patients lose at least as much copper in perspiration as normal subjects.

Copper Balance on $50 \mathrm{mg}$ Zinc 3 Times Per Day. Results of studies in 10 patients on this regimen 
TABLE 2. Copper concentration in forearm perspiration of Wilson's disease patients and controls*

\begin{tabular}{cccc}
\hline $\begin{array}{c}\text { Wilson's disease } \\
\text { patients } \\
\text { (our number) }\end{array}$ & $\begin{array}{c}\text { Copper concentration } \\
(\mu \mathbf{g} / \mathbf{d l})\end{array}$ & Controls & $\begin{array}{c}\text { Copper } \\
\text { concentration } \\
(\mu \mathbf{g} / \mathbf{d}) \text { ) }\end{array}$ \\
\hline 1 & 133.8 & 1 & 21.9 \\
3 & 8.1 & 2 & 24.6 \\
5 & 18.6 & 3 & 61.7 \\
7 & 222.6 & 4 & 52.3 \\
9 & 24.0 & 5 & 24.4 \\
10 & 64.0 & & \\
11 & 28.3 & $37.0 \pm 18.6$ \\
Mean $=$ & $71.3 \pm 79.3$ ( \pm 1 S.D.) \\
\multicolumn{4}{c}{$\mathrm{p}=$ nonsignificant (t test) } \\
\hline
\end{tabular}

a This study was performed by collecting perspiration from the forearm by placing the scrubbed hand and forearm in a trace elementfree plastic bag, sealed around the arm with elastic and having the person sit in a sauna at $93^{\circ} \mathrm{F}$ for $30 \mathrm{~min}$.

(Table 3) show that a negative or a neutral copper balance was achieved in all 10 individuals, with an overall mean negative balance of $-0.23 \pm 0.26 \mathrm{mg}$ copper per day.

Copper Balance on $50 \mathrm{mg}$ Zinc 2 Times Per Day. Negative or neutral balances were achieved in all three patients on this regimen, with a mean of $-0.18 \pm$ $0.40 \mathrm{mg}$ copper per day (Table 4).

Copper Balance on $25 \mathrm{mg}$ Zinc 4 Times Per Day. Negative or neutral copper balance resulted for all four patients on this regimen, with a mean of -0.23 $\pm 0.17 \mathrm{mg}$ copper per day (Table 5 ).

Copper Balance on $25 \mathrm{mg}$ Zinc 3 Times Per Day. Negative or neutral copper balance resulted with this regimen in all three patients, with a mean of -0.13 $\pm 0.07 \mathrm{mg}$ copper per day (Table 6).

Eleven of the 20 copper balances performed with various zinc treatment regimens were classified as a negative copper balance, and 9 were classified as neutral. Only four balances had slightly positive apparent balances of $0.03,0.07,0.07$ and $0.16 \mathrm{mg}$ per day, and these were classified as neutral because of assumed skin surface losses, as previously discussed. Overall, the observed copper balance averaged $-0.20 \mathrm{mg}$ per day. In contrast, in three Wilson's patients not on anticopper therapy, we have obtained blance results of $+0.75,+0.54$ and +0.69 , averaging $+0.66 \mathrm{mg}$ copper per day (Patients 2, 3 and 36 of the first column in Table 7 , and diamond symbols in Figure 1). The means of the balance data vs. daily dose of zinc are also illustrated in Figure 1, which includes data on $25 \mathrm{mg} 6$ times per day from a previous paper (Square symbol) (6). Comparison of the mean copper balance of the 15 patients taking $150 \mathrm{mg}$ zinc per day with the mean of the 10 patients taking a smaller dose (Figure 1) revealed no significant difference $(t=0.55, p$ $=$ not statistically significant). Further, regression of copper balance on total zinc dose for these 25 balances did not reveal a significant effect. We conclude that, in this group of patients, all in a relatively "decoppered" state, there was no evidence of a dose effect within the dose range studied. The main point is that all of the
TABLE 3. Average daily copper balance of Wilson's disease patients on $50 \mathrm{mg}$ zinc 3 times per day

\begin{tabular}{ccccc}
\hline $\begin{array}{c}\text { Patient } \\
\text { no. }\end{array}$ & Diet & Fecal & Urinary & Balance \\
\hline 3 & 1.06 & 0.94 & 0.05 & +0.07 \\
4 & 0.66 & 1.13 & 0.08 & -0.55 \\
5 & 1.43 & 1.57 & 0.10 & -0.24 \\
6 & 0.72 & 0.65 & $\mathrm{ND}^{a}$ & +0.07 \\
7 & 1.20 & 1.25 & 0.09 & -0.14 \\
9 & 0.52 & 0.63 & 0.03 & -0.14 \\
10 & 0.77 & 1.47 & 0.01 & -0.71 \\
12 & 0.86 & 1.16 & 0.05 & -0.35 \\
17 & 1.20 & 1.45 & 0.09 & -0.34 \\
24 & 1.61 & 1.52 & 0.06 & +0.03 \\
Mean & 1.003 & 1.18 & 0.056 & -0.23 \\
\hline
\end{tabular}

${ }^{a} \mathrm{ND}=$ not detectable with flame atomic absorption spectrophotometry (Perkin-Elmer).

TABLE 4. Average daily copper balance of Wilson's disease patients on $50 \mathrm{mg}$ zinc 2 times per day

\begin{tabular}{ccccc}
\hline $\begin{array}{c}\text { Patient } \\
\text { no. }\end{array}$ & Diet & Fecal & $\overline{\text { Urinary }}$ & Balance \\
\hline 1 & 1.09 & 1.73 & $\mathrm{ND}^{a}$ & -0.64 \\
4 & 1.11 & 1.11 & 0.06 & -0.06 \\
12 & 1.11 & 0.94 & 0.01 & +0.16 \\
Mean & 1.10 & 1.26 & & -0.18 \\
\hline
\end{tabular}

' $\mathrm{ND}=$ not detectable with flame atomic absorption spectrophotometry (Perkin-Elmer).

TABLE 5. Average daily copper balance in Wilson's disease patients on $25 \mathrm{mg}$ zinc 4 times per day

\begin{tabular}{ccccc}
\hline $\begin{array}{c}\text { Patient } \\
\text { no. }\end{array}$ & Diet & Fecal & $\begin{array}{c}\text { Copper (mg/day) } \\
\text { Urinary }\end{array}$ & Balance \\
\hline 1 & 1.27 & 1.47 & 0.03 & -0.23 \\
3 & 0.79 & 0.71 & 0.10 & -0.02 \\
5 & 0.49 & 0.83 & 0.02 & -0.36 \\
7 & 1.22 & 1.49 & 0.04 & -0.31 \\
Mean & 0.94 & 1.12 & 0.05 & -0.23 \\
\hline
\end{tabular}

TABLE 6. Average daily copper balance of Wilson's disease patients on $25 \mathrm{mg}$ zinc 3 times per day

\begin{tabular}{ccccc}
\hline $\begin{array}{c}\text { Patient } \\
\text { no. }\end{array}$ & Diet & Fecal & Urinary & Balance \\
\hline 1 & 1.42 & 1.39 & 0.06 & -0.03 \\
4 & 0.76 & 0.92 & 0.03 & -0.19 \\
17 & 0.89 & 0.97 & 0.08 & -0.16 \\
Mean & 1.02 & 1.09 & 0.06 & -0.13 \\
\hline
\end{tabular}

regimens produce satisfactory evidence of copper balance control.

Daily dietary intake of copper in the 20 patient-selected diets ranged from 0.49 to $1.61 \mathrm{mg}$ with an average of $1.01 \mathrm{mg}$ (Tables 3 to 6). As expected, fecal copper loss was the main route of copper excretion, resulting from 
TABLE 7. Copper balance data on Wilson's disease patients on no treatment (Patients 2,3 and 36 ) and serial copper balance data on patients who have had more than one balance ${ }^{a}$ (total dose of zinc in parentheses)

\begin{tabular}{|c|c|c|c|c|c|c|}
\hline \multirow{2}{*}{$\begin{array}{c}\text { Patient } \\
\text { no. }\end{array}$} & \multicolumn{6}{|c|}{ Monthly intervals of subsequent studies after first study } \\
\hline & $\mathbf{0}$ & $1-6$ & $7-12$ & 13-18 & 19-24 & 25-30 \\
\hline 1 & $-0.42(150)^{a}$ & & & $-0.23(100)$ & $-0.03(75)$ & $-0.64(100)$ \\
\hline 3 & $+0.54(0)$ & & $-0.02(150)^{a}$ & $-0.02(100)$ & $+0.07(150)$ & $-0.13(100)$ \\
\hline 4 & $-0.16(150)^{a}$ & $-0.55(150)$ & $-0.19(75)$ & $-0.06(100)$ & & \\
\hline 5 & $-0.03(150)^{a}$ & & $-0.36(100)$ & & $-0.24(150)$ & \\
\hline 12 & $-0.35(150)$ & & $+0.16(100)$ & & & \\
\hline 17 & $-0.34(150)$ & $-0.16(75)$ & & & & \\
\hline 36 & $+0.69(0)$ & & & & & \\
\hline
\end{tabular}

" Data are included from a previous paper (6) in which the daily dose was $150 \mathrm{mg}$ ( $25 \mathrm{mg}, 6$ times per day).

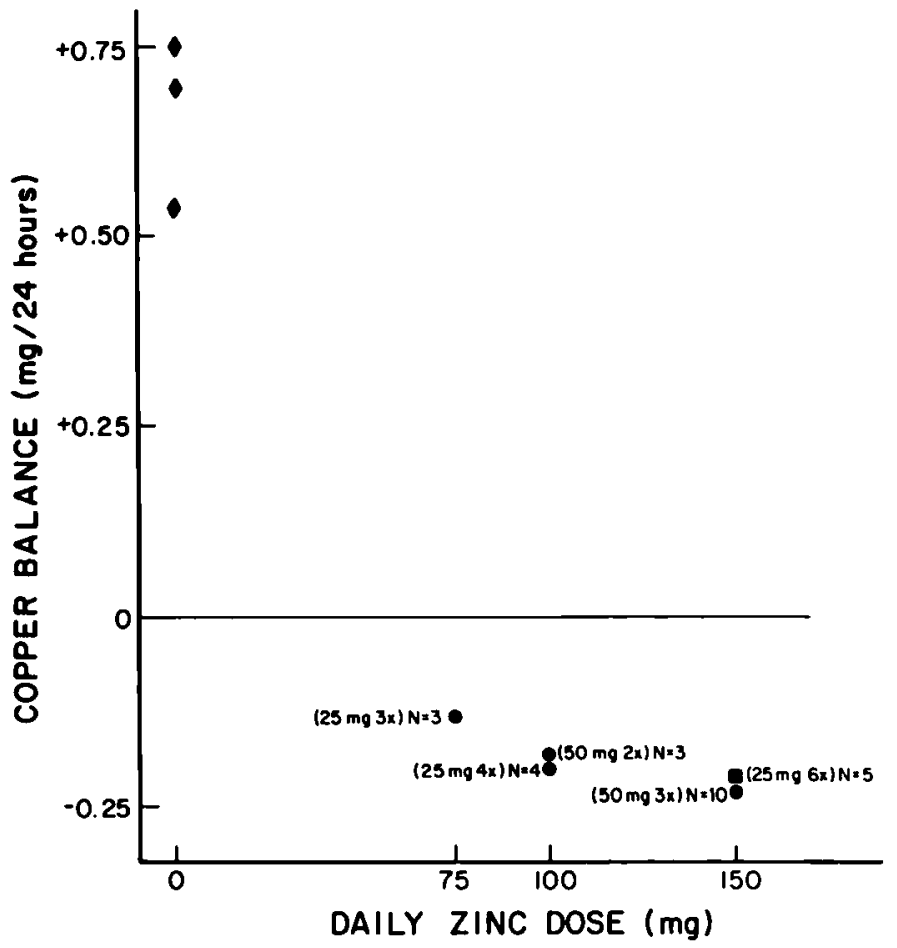

FIG. 1. The mean copper balances on the four zinc regimens studied in this paper (circles) plus the mean copper balance data from a previously studied regimen (square) (6) are plotted against daily intake of zinc. In addition, copper balance obtained from three patients while not on anticopper therapy are plotted (diamonds). The means and standard deviations for the various treatments shown on this figure are as follows: $25 \mathrm{mg} 3 x=-0.13 \pm 0.07 ; 25 \mathrm{mg} 4 \times=-0.23 \pm 0.17 ; 50 \mathrm{mg}$ $2 x=-0.18 \pm 0.40 ; 50 \mathrm{mg} 3 x=-0.23 \pm 0.26 ; 25 \mathrm{mg} 6 x=-0.21 \pm$ 0.21 .

zinc therapy and ranged from $0.63 \mathrm{mg}$ per day for Patient 9 (50 mg 3 times per day) to $1.73 \mathrm{mg}$ per day for Patient 1 (50 mg 2 times per day), and averaged $1.15 \mathrm{mg}$ per day (all data pooled).

Table 7 provides copper balance data on three Wilson's disease patients on no therapy at the time of balance (Patients 2, 3 and 36, first column). Patients 2 and 3 had been previously extensively treated with penicillamine, while Patient 36 had not. Nonetheless, the three positive balances are quite similar. Table 7 also provides serial copper balance data in the same patients, with approxi- -mate time intervals in months indicated. The total daily dose of zinc at the time of the balance is indicated in parentheses. As was the case with the entire body of data, there is no apparent dose response trend in individual patients. Further, there is no evidence of "tolerance" to zinc, resulting in a lessening effect as patients are on the therapy for long periods of time.

\section{DISCUSSION}

Thirteen of the patients studied were relatively well "decoppered" as evidenced by disappearance of KayserFleischer rings, relatively low urinary copper excretion and low values for nonceruloplasmin plasma copper (Table 1). During this study while on only continuous zinc therapy, a decoppered state was maintained as shown by low urinary excretion of copper and low nonceruloplasmin plasma copper (Table 1). These previously "decoppered" patients were maintained in negative or neutral copper balance with all of the regimens which were studied. As previously defined, 11 of the balance studies were negative and 9 were neutral. Actual values show four small positive balances $(+0.07,+0.07,+0.03$ and +0.16 ) which, when considering the probable losses of copper in insensitive perspiration, are defined as neutral. Thus, in all 20 studies, zinc maintained an adequate control of copper balance. This is illustrated dramatically by contrasting these results with those of three untreated patients (diamond symbols in Figure 1; mean positive balance of $0.66 \mathrm{mg}$ ).

Previous estimates in the literature indicated that copper intakes of the general population were in the range of 2 to $5 \mathrm{mg}$ per day (14), and the National Academy of Sciences, National Research Council set a safe and adequate intake level of 2 to $3 \mathrm{mg}$ of copper per day for adults (15). However, more recent work has indicated that the earlier estimates are much too high and that the actual copper intake of most Americans is around $1.0 \mathrm{mg}$ or less per day (16-18). We have confirmed that the intake of copper in self-selected diets of six normal subjects is about $1.0 \mathrm{mg}$ per day (Hill, G. M. et al., Am. J. Clin. Nutr. 1982; 35:XXI, Abstract). Thus, the diets of our Wilson's disease patients contained, on average, about the same amount of copper that Americans consume and were not abnormally low. Further, the 
diet while in the hospital was selected by each patient to be similar to that being ingested at home.

To document that one particular simplified regimen of zinc therapy would adequately control copper balance in Wilson's disease patients, we selected $50 \mathrm{mg} 3$ times per day and performed 10 studies with this regimen. The data in the 10 individual patients in Table 3 demonstrate adequate control in each case. Further, the mean effect on balance from this $150 \mathrm{mg}$ daily dose is comparable to the mean effect of the $150 \mathrm{mg}$ daily dose given by the more tedious $25 \mathrm{mg} 6$ times per day previously reported, as shown in Figure 1. Thus, we conclude on the basis of the data in Table 3 that $50 \mathrm{mg}$ zinc taken 3 times per day is generally effective in controlling copper balance in Wilson's disease.

To develop preliminary data on other simplified regimens, including the effect of reduction of total daily zinc dose, the 10 studies in Tables 4 to 6 were performed. Again, they illustrate adequate individual control of copper balance with each regimen, even with doses as low as $75 \mathrm{mg}$ zinc per day. However, because of the limited number of studies, the evidence of efficacy of these lower doses must be viewed as preliminary. Over the dose range studied, there is no evidence of dose response to zinc in terms of an effect on copper balance in these well "decoppered" patients. As shown in Table 7, there is no indication of a "tolerance" to zinc developing.

Zinc has been shown to induce intestinal metallothionein (19) which binds zinc and copper in the intestine and prevents their serosal transfer (20). Intestinal cells are sloughed with about a 6-day turnover (21), and the metallothionein-bound copper and zinc are lost in the stool and are thus not absorbed. Adequate zinc status is probably necessary for metallothionein induction to occur. To assure adequate zinc status before the copper balance studies, all patients were pretreated with the zinc regimen to be tested for 3 months prior to admission. Metallothionein in various tissues of the rat appears to have a half-life of at least $12 \mathrm{hr}(22)$, indicating that large doses of zinc, twice daily, should theoretically be adequate to continually stimulate metallothionein production for blocking copper uptake. The results reported here support this theoretical consideration and indicate that a frequency of zinc administration as low as twice a day is effective, at least in the three patients studied (Table 4). In patients who have gastric intolerance of the $50 \mathrm{mg}$ dose, it appears that $25 \mathrm{mg}$ zinc taken 3 or 4 times per day is effective, although we have less experience with this regimen (Tables 5 and 6 ).

Fecal copper comes from: (i) unabsorbed dietary copper and (ii) copper of endogenous secretions which was not reabsorbed. In rat studies, complexed copper of biliary secretions appears to be less available for reabsorption than copper in saliva, pancreatic juice, gastric juice and intestinal secretions (23). Salivary and gastric secretions in Wilson's disease patients contain approximately 0.45 and $1.0 \mathrm{mg}$ copper per $24 \mathrm{hr}$, respectively (24). If the secretions of the intestines contain at least $0.2 \mathrm{mg}$ copper per day, approximately $1.65 \mathrm{mg}$ of copper is contained in the daily endogenous secretions of a Wilson's disease patient. Thus, the negative copper balance produced by zinc therapy probably comes from at least partial blockade of absorption of both dietary and endogenously secreted copper, resulting in high fecal excretion of copper.

In our clinic, 39 patients are now on maintenance therapy with zinc, 14 for over 2 years; in each case, initial copper balance has been employed to demonstrate adequacy of therapy. Subsequently, these patients are monitored by a variety of techniques, including ${ }^{64}$ copper utpake (25), liver biopsy, measurement of urine and plasma copper and thorough clinical follow-up. In each case, zinc has proven effective in preventing the reaccumulation of copper and the occurrence or reoccurrence of symptoms. To date, in 10 previously decoppered patients with serial liver biopsies over the course of 1 to 3 years, zinc therapy has been shown to prevent the reaccumulation of hepatic copper (Brewer, G. J. et al., Clin. Res. 1985; 33:871A, Abstract).

Our experience with zinc therapy has primarily been with patients previously treated for several years with penicillamine, and who are thus relatively well-decoppered, as manifested for example, by a 24-hr urine copper when off penicillamine therapy of $200 \mu \mathrm{g}$ or less, and a nonceruloplasmin plasma copper of $25 \mu \mathrm{g}$ or less. Thus, at present, patients of this type who are intolerant of penicillamine are the major candidates for zinc therapy. The use of zinc as an initial decoppering agent is currently under investigation.

We conclude that decoppered Wilson's disease patients can be kept in negative or neutral copper balance with a simplified regimen of zinc therapy. The regimen we currently use for most of our patients is $50 \mathrm{mg} 3$ times per day. Patients to be placed on zinc therapy should be carefully monitored by as many of the following procedures as possible: ${ }^{64}$ copper uptake; liver biopsy; urine and plasma copper; copper balance if available, and of course by clinical observation.

Acknowledgments: The authors wish to acknowledge Dr. Z. T. Cossack, who assisted in the initial studies, $R$. Dick, K. Jasti and N. Aquino for technical assistance, and Stella Gotts and Charlotte Wooden for manuscript preparation.

\section{REFERENCES}

1. Walshe JM. Penicillamine. A new oral therapy for Wilson's disease. Am J Med 1956; 21:487-495.

2. Sass-Kortsak A. Wilson's disease. A treatable disease in children. Pediatr Clin North Am 1975; 22:963-984

3. Borthwick TR, Benson GD, Schusar JH. Copper chelating agents: a comparison of cupruretic responses to various tetramines and $D$ penicillamine. J Lab Clin Med 1980; 95:575-80.

4. Smith SE, Larson EJ. Zinc toxicity in rats: antagonistic effects of copper on liver. J Biol Chem 1946; 163:29-38.

5. Brewer GJ, Schoomaker EB, Leichtman DA, et al. The use of pharmacological doses of zinc in the treatment of sickle cell anemia. In: Brewer GJ, Prasad AS, eds. Zinc metabolism: current aspects in health and disease. New York: Alan R. Liss, Inc., 1977: 241-254.

6. Brewer GJ, Hill GM, Prasad AS, et al. Oral zinc therapy for Wilson's disease. Ann Intern Med 1983; 99:314-320.

7. Hoogenraad TU, Van Den Hamer CJA, Koevoet R, et al. Oral zinc in Wilson's disease. Lancet 1978; 2:1262-1269.

8. Hoogenraad TU, Koevoet R, de Ruyter Korver EGWM. Oral zinc suphate as long-term treatment in Wilson's disease (hepatolenticular degeneration). Eur Neurol 1979; 18:205-211.

9. Hoogenraad TU, Van Den Hamer CJA. Three years of continuous 
oral zinc therapy in 4 patients with Wilson's disease. Acta Neurol Scand 1983; 67:356-364.

10. Oelshlegel FJ, Brewer GJ. Absorption of pharmacological doses of zinc. In: Brewer GJ, Prasad AS, eds. Zinc metabolism: current aspects in health and disease. New York: Alan R. Liss, Inc., 1977: 299-311.

11. Pecoud A, Dozel P, Schelling JL. The effect of foodstuffs on the absorption of zinc sulfate. Clin Pharmacol Ther 1975; 17:469-474.

12. Jacob RA, Sandstead HH, Muñoz JM, et al. Whole body surface loss of trace metals in normal males. Am J Clin Nutr 1981; 34:1379 1383.

13. Cochran WG, Snedecor GW. Statistical methods. Ames, Iowa: The Iowa State University Press, 1972.

14. Underwood $\mathbf{E} J$. Trace elements in human and animal nutrition. New York: Academic Press, 1977.

15. National Research Council. Recommended dietary allowances. Washington, D.C.: National Academy of Science, 1980.

16. Klevay LM, Reck SJ, Barcome DP. Evidence of dietary copper and zinc deficiencies. JAMA 1979; 241:1916-1918.

17. Holden JM, Wolf WR, Mertz W. Zinc and copper in self selected diets. J Am Diet Assoc 1979; 75:23-28.

18. Reiser S, Smith JC Jr, Mertz W, et al. Indices of copper status in humans consuming a typical American diet containing either fructose or starch. Am J Clin Nutr 1985; 42:242-251.

19. Menard MP, McCormick CC, Cousins RJ. Regulation of intestinal metallothionein biosynthesis in rats by dietary zinc. J Nutr 1981; 111:1353-1361.

20. Fischer PWF, Giroux A, L-Abbe MR. Effects of zinc on mucosal copper binding and on the kinetics of copper absorption. $J$ Nutr 1983 ; 113:462-469.

21. MacDonald WC, Trier JS, Everett NB. Cell proliferation and migration in the stomach, duodenum, and rectum of man: radioautographic studies. Gastroenterology 1964; 46:405-417.

22. Bremner I, Hoekstra WG, Davies NT, et al. Effect of zinc status of rats on synthesis and degradation of copper-induced metallothionein. Biochem J 1978; 174:883-892.

23. Gollan JL. Studies on the nature of complexes formed with human alimentary secretions and their influence on copper absorption in the rat. Clin Sci Molec Med 1975; 49:237-245.

24. Gollan JL. Copper content of human alimentary secretions. Clin Biochem 1971; 4:42-44.

25. Hill GM, Brewer GJ, Junie JE, et al. Treatment of Wilson's disease with zinc: II. Validation of oral ${ }^{64}$ copper with copper balance. Am J Med Sci 1986; 29:344-349. 